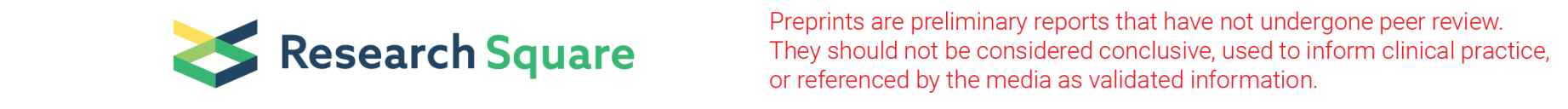

\title{
Determinants of anemia among HIV positive children on Highly Active Antiretroviral Therapy (HAART) attending hospitals of North Wollo Zone, Amhara Region, Ethiopia, 2019: A case-control study
}

Biruk Beletew Abate ( $\sim$ Birukkelemb@bmcph.com )

Weldia university

Ayelign kassie

Woldia University

Mohammed Ahmed

Woldia University

Research article

Keywords: Children, Anemia, HAART, North Wollo Zone, Ethiopia

Posted Date: August 20th, 2019

DOI: https://doi.org/10.21203/rs.2.13201/v1

License: (c) This work is licensed under a Creative Commons Attribution 4.0 International License. Read Full License 


\section{Abstract}

Introduction Anemia is one of the most commonly observed hematological abnormalities and an independent poor prognostic marker of HIV disease. The rate of progression and mortality in this subgroup of patients is high compared to non-anemic patients. WHO estimates that over 2 billion people are anemic worldwide and young children bear the world's highest prevalence rate of anemia. In Ethiopia, there is limited information about the determinant factors associated with anemia among HIV positive children. Objective The main purpose of this study was to assess the determinants of anemia among children on highly active anti-retroviral therapy attending hospitals of North Wollo Zone, Amhara Region, Ethiopia. Methods A case-control study was conducted on 350 HIV infected children on HAART attending Hospitals of North Wollo Zone, from February 1 to March 30, 2019. The study participants were selected with consecutive sampling technique. An adapted, interviewer-administered, and pre-tested questionnaire and chart review were employed to collect the data. Besides, blood and stool sample was investigated to determine hematologic indices and malaria and to investigate intestinal parasites respectively. Data were analyzed by using the SPSS version 24 statistical software and bivariate and multivariate logistic regression was used to identify predictors. Results A total of $350 \mathrm{HIV}$ positive children (117 cases and 234 controls) were included in this study with an overall response rate of $100 \%$.On multivariate analysis, variables which have spastically significance association with anemia were; had Amebiasis (AOR = 7.29, 1.22 - 43.56), had history of opportunistic infections (AOR = 9.63, 1.94 - 47.85), had malaria infection (malaria pf) (AOR = 4.37, 1.16 - 16.42),eating non-diversified $(A O R=10.39,2.25$ - 48.0), WGT -Age Z score value between -2_-3 (AOR = 9.80, 2.46 - 39.14),level of adherence $(A O R=2.31,1.92,7.77)$ and being from rural area(AOR = 8.8, $2.07-37.79)$. Conclusion In this study having parasitic infections, history of opportunistic infections, being malnourished, poor adherence to ART, caregivers living in the rural area and eating non-diversified foods were significantly associated with anemia among HIV positive children on HAART.

\section{Background}

HIV is still a global problem causing extensive morbidity and mortality worldwide, especially in sub-Saharan Africa, where more than $70 \%$ of all HIV cases occur. (1-4). Hematological abnormalities are a common occurrence in individuals diagnosed with human immunodeficiency virus (HIV) (5-9), of these hematological abnormalities anemia is the most common in HIV-infected children that have a significant impact on the quality of life and clinical outcomes. (7-9)

According to World Health Organization (WHO) definitions, anemia is defined as hemoglobin level less than $11 \mathrm{~g} / \mathrm{dl}$ for children $<5$ years old, $<11.5 \mathrm{~g} / \mathrm{dl}$ for children $5-11.9$ years old and $<12 \mathrm{~g} / \mathrm{dl}$ for children $12-14.9$ years old after altitude adjustment (10). Anemia is classified as mild degree (Hgb 10.0-10.9 g/dl), moderate (Hgb 7.0-9.9 g/dl), severe (Hgb 4.0$7.0 \mathrm{~g} / \mathrm{dl}$ ), and very severe Hgb less than $4.0 \mathrm{~g} / \mathrm{dl}$. It can also be classified based on the hematocrit (PCV) percent. Packed cell volume (PCV) of less than $33.0 \%$ is regarded as anemia by the World Health Organization. (10)

The risk factors of anemia are multiple and vary across geographical areas. In HIV-infected patients, anemia may be caused by nutrient deficiencies (iron, folic acid, and vitamin B12), sickle cell disease, HIV/AIDS itself, malaria, hookworm, and other infections. Iron deficiency anemia is the leading(50\%) cause of childhood anemia in developing countries (8, 9 , 11)

In addition to the direct effect of HIV, highly active antiretroviral therapy (HAART) also causes anemia. Although HAART has the capability of reducing the incidence of anemia [17] by suppressing viral replication and increases CD4 cell count, anemia remains a common problem even for patients treated with antiretroviral agents. Anemia due to drugs, such as cotrimoxazole, pentamidine, foscarnet, and zidovudine (AZT) often reflects reticuloendothelial iron block. (12)

There are several factors believed to contribute to the pathophysiology of anemia observed in HIV patients. First, many of the opportunistic infections or malignancies to which HIV patients are susceptible can lead to anemia(13).

Page 2/18 
As with anemia in the HIV population, micronutrient deficiencies can play a role in contributing to anemia in HIV patients (13). Finally, many of the most common ART drugs included in the standard also harm hematopoiesis and can thus contribute to anemia in HIV. The molecular mimicry between erythropoietin (EPO) and the HIV-1 p17 protein can lead to circulating auto-antibodies against endogenous EPO in some HIV patients $(4,13)$.

Anemia is a common co-morbid condition among HIV infected children and has a profound impact on disease progression and has been noted as a significant predictor of decreased survival time and death $(14,15)$. Especially children are more prone to the consequences of anemia due to high iron requirements, low intake of iron from foods, and frequent episodes of infection (10).

Anemia is one of the global public health problems that affect more than one-third of the world population. It has been strongly associated with poor growth and development, limited psychomotor development, and poor long-term performance in cognitive, social, and emotional functioning in children. It is also associated with impaired mental, physical and language development; and poor coordination, scholastic achievement and immune function (16).

Also, the outcomes of anemia can be considered from a variety of perspectives, including stunt growth, increase morbidity from infectious diseases, detrimental impacts on economic and social development $(2,17)$.

According to World Health Organization (WHO) 2015 report, about 43\% of under-five children were anemic, with regional variations of $62.3 \%$ in African, $53.8 \%$ in South-East Asia and $21.9 \%$ in Western Pacific Region $(8,13)$.

Anemia is a common childhood health problem in Africa, and its prevalence among children under the age of five years is estimated at $62 \%$, which is above the cut off points (40\%). It is a leading cause of pediatric mortality and impaired development and is highly prevalent in young children in sub-Saharan Africa $(9,18)$.

In Ethiopia As many as six in ten under-five children are anemic (19). As per EDHS 2016, Overall, more than half of children 6-59 months (56 percent) suffered from some degree of anemia: 25 percent were mildly anemic, 28 percent were moderately anemic, and 3 percent were severely anemic(11). Despite causing such high levels of burden, the public health community does not pay anemia the attention it deserves.

The government of Ethiopia has been working to reduce childhood anemia. Accordingly, it endorsed the national nutrition program, bimanual school deworming, developed micronutrient deficiency prevention and control guideline and implemented micronutrient fortification. But studies from different corners of the country have shown that childhood anemia is still a major public health problem in this country(20).

Most of the studies on the HIV-anemia interplay were done in developed countries and mainly included adults. Determinants of anemia among HIV/AIDs positive children on HAART has not been very well understood in resource-poor settings like Ethiopia, although there are few crossectional studies conducted at different parts of the country. However, knowing the determinants of anemia among HIV/AIDS positive children on HAART through the case-control study will help to screen and manage anemia according to its cause. Therefore this study intends to fill these gaps by identifying the determinant factors of anemia among HIV positive children on HAART.

\section{Objectives}

\section{General Objective}

- To assess determinant factors of anemia among HIV Positive Children on Highly Active Antiretroviral Therapy (HAART) attending hospitals of North Wollo Zone, Amhara, Ethiopia, 2019. 


\section{Specific objectives}

- To identify socio-demographic factors associated with anemia among HIV Positive Children on Highly Active Antiretroviral Therapy.

- To determine nutritional related factors associated with anemia among HIV Positive Children on Highly Active Antiretroviral Therapy.

- To identify drug-related factors associated with anemia among HIV Positive Children on Highly Active Antiretroviral Therapy.

- To identify disease-related factors associated with anemia among HIV Positive Children on Highly Active Antiretroviral Therapy.

\section{Methodology Study Area}

This study was carried out in North Wollo Zone Hospitals, Amhara region, Ethiopia. According to the 2007 Census conducted by the Central Statistical Agency of Ethiopia (CSA), this Zone has a total population of 1,500,303, of whom 752,895 are men and 747,408 women. The largest ethnic group in North Wollo is the Amhara (99.38\%), and all other ethnic groups made up $0.62 \%$ of the population. Amharic is spoken as a first language by $99.28 \%$ of the population and the remaining $0.72 \%$ spoke other primary languages. $82.74 \%$ of the populations are Ethiopian Orthodox Christianity followers, and $17.08 \%$ are Muslims. There are 5 public hospitals in this zone. These are Kobo Hospital (KH), Lalibela hospital (LH), Shediho Meket Hospital (MH), Wadla hospital (WH) and Woldia general hospital (WGH).

\section{Study Design and Period}

A health facility-based case-control study was conducted from February 1 to March 30, 2019.

\section{Population}

\section{Source Population}

All HIV Positive Children on Highly Active Antiretroviral Therapy (HAART) attending hospitals of North Wollo Zone, Amhara, Ethiopia.

\section{Study Population}

All HIV Positive Children on Highly Active Antiretroviral Therapy (HAART) attending selected hospitals of North Wollo Zone, Amhara, Ethiopia.

\section{Sample Size Determination}

The sample size is determined using a double population proportion difference formula by using major determinant variables such as iron deficiency, inflammation, underweight, malaria Pf, albumin deficiency, and ART regimen. Since it gives the maximum sample size, iron deficiency was considered as an independent predictor (exposure) variable (Table 1). From that study, the proportion of children among cases with iron deficiency was $26.9 \%$ and the proportion of children 


\section{Table 1: Sample size calculation from determinant factors of anemia among children on HAART attending selected hospitals of North Wollo Zone, Amhara, Ethiopia.}

\begin{tabular}{|l|c|c|c|c|}
\hline Variable & Proportions & \multicolumn{3}{|c|}{ Sample size } \\
\cline { 3 - 5 } & & Cases & Controls & Total \\
\hline Under WGT & $\begin{array}{l}\mathrm{P} 1=44 \% \\
\mathrm{P} 2=11 \%\end{array}$ & 62 & 124 & 186 \\
\hline Iron deficiency & $\begin{array}{l}\mathrm{P} 1=69 \% \\
\mathrm{P} 2=43 \%\end{array}$ & 117 & 234 & 350 \\
\hline Malaria pf & $\mathrm{P} 1=42 \%$ \\
& $\mathrm{P} 2=7 \%$ & 52 & 104 & 156 \\
\hline Albumin deficiency & $\begin{array}{r}\mathrm{P} 1=41 \% \\
\mathrm{P} 2=4 \%\end{array}$ & 44 & 88 & 132 \\
\hline
\end{tabular}

$n=\left((r+1) *\left(p_{1} q_{1}+p_{2} q_{2}\right)\left(Z_{\beta}+Z_{\alpha / 2}\right)^{2}\right) /\left(r\left(P_{1}-P_{2}\right)^{2}\right)$

Where,

$\mathrm{n}$ : sample size in the case group

$Z_{\alpha / 2:}$ The desired power (90\% power)

$\mathrm{P}_{1}-\mathrm{P}_{2}$ : Effect size (the difference in proportions)

$\mathrm{P} 1$ : is a percent of cases with exposure variable

P2: is the percent of controls with exposure variable and

$r:$ is the ratio of cases to controls $1: 2$

\section{Sampling Technique and procedure}

Simple random sampling technique was employed to select the required number of cases and controls attending hospitals in North Wollo Zone. First, out of the total 5 hospitals in North Wollo Zone, 3 hospitals were selected through simple random sampling technique. Then, the required sample size was allocated proportionally to the selected hospitals based on the number of cases and controls. Study participants (cases and controls) in the selected hospitals were selected using consecutive sampling technique by considering client flow is random. Cases were selected consecutively among HIV positive children's on HAART in the selected hospitals. The next immediate two corresponding age and sexmatched controls were selected consecutively among HIV positive children on HAART in the selected hospitals.

\section{Variables}




\section{Independent variables}

- Socio-demographic variables

- Ethnicity

- Residence

- Religion

- Occupation of mother

- Family size

- Household wealth index status

- Altitude

- The educational level of a mother

- The educational level of father

- Age

- Sex

- Disease-related

- Cd4 count / percentage

- WHO stage

- Stool result (IP)

- Malaria history

- Opportunistic infection (OPs)

- Inflammation (ultrasensitive CRP > 1.0) mg/dl)

- Past medical history

- Drug-related

- HAART duration

- HAART status (new....experienced...

- HAART regimen

- Cotrimoxazole

- Previous and current drug history,

- Nutritional related variables

- Dietary Diversity Score

- Nutritional status

\section{Eligibility Criteria}

\section{Inclusion criteria}

\section{Inclusion criteria for cases}


HIV Positive Children on Highly Active Antiretroviral Therapy (HAART) who were anemic and may not be diagnosed with other medical illness.

\section{Inclusion criteria for controls}

HIV Positive Children on Highly Active Antiretroviral Therapy (HAART) who were not anemic, age and sex-matched with cases

\section{Exclusion criteria}

\section{Exclusion criteria for cases}

Children with an incomplete chart, children passed-away on arrival, children admitted without their caregiver.

\section{Exclusion criteria for controls}

Children with an incomplete chart, children passed-away on arrival, children admitted without their mothers.

\section{Definitions of terms and operational definitions}

Case (anemia) - HIV Positive Children on Highly Active Antiretroviral Therapy (HAART) whose Hg level is less $11 \mathrm{~g} / \mathrm{dl}$ for children $<5$ years old, $<11.5 \mathrm{~g} / \mathrm{dl}$ for children $5-11.9$ years old and $<12 \mathrm{~g} / \mathrm{dl}$ for children $12-14.9$ years old or may not be diagnosed with other medical illness (31).

Control (non anemic) HIV Positive Children on Highly Active Antiretroviral Therapy (HAART) whose Hg level is more than or equal to $11 \mathrm{~g} / \mathrm{dl}$ for children $<5$ years old, $11.5 \mathrm{~g} / \mathrm{dl}$ for children $5-11.9$ years old and $12 \mathrm{~g} / \mathrm{dl}$ for children $12-14.9$ years old age and sex-matched.

Mild anemia-((Hgb 10.0-10.9 g/dl),

Moderate anemia - $(\mathrm{Hgb} 7.0-9.9 \mathrm{~g} / \mathrm{dl})$,

Severe anemia- $\mathrm{Hb}<7.0 \mathrm{~g} / \mathrm{dl}$ for children aged 6-59 months; and $\mathrm{Hb}<8.0$ for those 5 years and older $(32,33)$

Very severe anemia - Hgb less than $4.0 \mathrm{~g} / \mathrm{dl}$

\section{Data Collection tool and Procedure}

Data was collected by face to face interview, chart review and anthropometric measurement with pretested and structured questionnaire adapted from previous similar literature. A review of the medical records was performed for concurrent opportunistic infections and WHO clinical staging of HIV disease. Laboratory investigation was performed by laboratory professionals to determine the hemoglobin level of participants and identify possible malaria and other parasitic infections (30). The questionnaire had 5 parts: Part1- Socio-demographic/economic variables, Part 2: Assessment of degree and type of anemia, part 3: Disease-related determinants of anemia, part 4: Drug-related determinants of anemia, and part 5: Nutritional status-related determinants of anemia. 
Nutritional assessment: Dietary Diversity Score (DDS) was calculated from a single 24-hour dietary recall data. Additionally, study participants were screened for nutritional status using anthropometric measurements.

Chart review was done to identify hemoglobin concentration ( $\mathrm{Hgb})$, blood history of malaria and Viral load.

Stool specimen collection and examination: A stool sample was collected from each study participants using clean, widemouthed and leak-proof stool cup by laboratory professionals. Then, stool wets mount was prepared using saline and/or iodine and examined microscopically for identification of intestinal helminths.

\section{Data quality control}

A pretest was conducted on 5\% (17) of the sample size among children on HAART attending Dessie referral hospital which was not included in the study settings and was selected by lottery method among the hospitals not included in the study settings. The pretest study was conducted 2 weeks before the actual data collection period. The study participants who fulfill the inclusion criteria were selected by simple random sampling technique. The result of the pretest was discussed and all the necessary amendments were made on, the instructions, contents, order and grammatical issues based on the results of the pretest.

Three-day intensive training was given for data collectors and supervisors on the overall data collection procedure to minimize systematic errors. A clear explanation of the purpose and objective of the study was provided for the respondents at the beginning of the interview. On spot-checking and correction was made for incomplete questionnaires by supervisors. Laboratory test quality was assured by giving training for laboratory professionals by MSc laboratory professionals using the standard operating procedure (SOP) and regular monitoring of reagents for manufacturing, expiry date, and proper storage. The sample was processed immediately after collecting from the study participants to minimize errors and the overall data collection process was monitored by investigators.

\section{Data analysis and presentation}

The filled questionnaires were checked for completeness, coded and entered into Epi Data version 4.2 and then exported to SPSS version 24 for further analysis. Descriptive statistics were computed and the result was reported using frequencies and percentages. Bivariate logistic regression was performed and variables with $p<0.25$ were transported to multivariable logistic regression. Finally, variables with P-value $<0.05$ in the multivariable logistic regression model were taken as statistically significant and adjusted odds ratio with its $95 \%$ confidence interval was considered to see the strength of association between the exposure variables and the outcome of interest.

\section{Ethical consideration}

Ethical clearance was obtained from the Woldia University research ethics committee and it approves the whole part of the research including the method. Permission and support letter was sought and obtained from the North Wollo Zone Health Office. Then, officials at different levels in the hospitals were communicated through letters. The responsible bodies at each hospital were told about the purpose of the study. Written informed consent was obtained from parents of every study participants after a detailed explanation on the purpose and benefit of the study right before data collection and assent was obtained from the study participants and the ethics committee approved this procedure. The respondents were notified that they have the right to refuse or terminate at any point during data collection. All data collectors and supervisors were instructed on how to comply with strict confidentiality practices for all participants both during and after data collection. The identity of the participants was kept anonymous. 


\section{Dissemination of the result}

The results of the study were disseminated to Woldia University, faculty of health science, research directorate office. Furthermore; the findings and recommendations of the study will also be shared in a written document to North Wollo Zone Health Office and Hospitals in North Wollo Zone. After public defense and incorporation of comments, the result will also be disseminated through presentations on research conferences, workshops, and symposiums. Finally, the attempt will be made to publish in a reputable peer-reviewed journal. The study participants will remain anonymous during and after publication. The owners of the research are the researchers and Woldia University

\section{Results}

\section{Socio-demographic characteristics of the respondents}

A total of 350 HIV positive children (117 cases and 234 controls) were included in this study with an overall response rate of $100 \%$. One hundred eighty-two $182(52 \%)$ of them were females. The mean and the median age of the child were 8.91 and 3.14 years respectively. Most of the participants were from urban areas (24.2\%\% cases and $34.9 \%$ controls). Most of the study participants, 206 (58.9\%) were Orthodox Christian followers followed by Muslims, 110 (31.4\%). Regarding the marital status of mothers, $72(20.6 \%)$ of cases and $136(38.9 \%)$ controls were married. Concerning the educational status of mothers, $59(16.9 \%)$ of cases and $85(24.3 \%)$ controls were illiterate and the remaining were able to read and write or had completed primary education and above. Regarding occupation of mothers, majority of them 66(18.9\%) of cases $83(23.7 \%)$ controls were non-employed and $44(12.6 \%)$ of cases and $83(23.7 \%)$ controls were housewives. From the total study participants, $42(12.0 \%)$ of cases and 146 (41.7\%) controls were from middle-income class families (Table 1).

\section{Table 2: Socio-demographic characteristics of children on HAART and their parents in North Wollo Zone public hospitals, Amhara region, Ethiopia, 2019 ( $n$ = 350).}




\begin{tabular}{|c|c|c|c|}
\hline \multirow[t]{2}{*}{ Exposure variable } & \multirow[t]{2}{*}{ Responses } & \multicolumn{2}{|c|}{ Anemia Status } \\
\hline & & $\begin{array}{c}\text { Anemic } \\
\text { Count (\%) }\end{array}$ & $\begin{array}{c}\text { Non-anemic } \\
\text { Count }(\%)\end{array}$ \\
\hline \multirow[t]{3}{*}{ Ethnicity } & Amhara & $113(32.3)$ & $217(62.0)$ \\
\hline & Oromo & $1(0.3)$ & $5(1.4)$ \\
\hline & Tigrie & $3(0.9)$ & $11(3.1)$ \\
\hline \multirow[t]{4}{*}{ Educational status of the Mother } & Cannot read and write & $59(16.9)$ & $85(24.3)$ \\
\hline & Can read and write & $45(12.9)$ & $80(22.9)$ \\
\hline & Primary & $12(3.4)$ & $59(16.9)$ \\
\hline & Secondary and above & $1(0.3)$ & $9(2.6)$ \\
\hline \multirow[t]{4}{*}{ Educational status of the father } & Cannot read and write & $53(15.1)$ & $89(25.4)$ \\
\hline & Can read and write & $51(14.6)$ & $58(16.6)$ \\
\hline & Primary & $6(1.7)$ & $63(18.0)$ \\
\hline & Secondary and above & $7(2.0)$ & $23(6.5)$ \\
\hline \multirow[t]{4}{*}{ Occupation of the mother } & Not employed & $66(18.9)$ & $83(23.7)$ \\
\hline & Housewife & $44(12.6)$ & $83(23.7)$ \\
\hline & Governmental employee & $6(1.7)$ & $62(17.7)$ \\
\hline & An employee in the private sector & $1(0.3)$ & $5(1.4)$ \\
\hline \multirow[t]{3}{*}{ Religion } & Orthodox & $72(20.6)$ & $134(38.3)$ \\
\hline & Muslim & $31(8.9)$ & $79(22.6)$ \\
\hline & Others & $14(4)$ & $20(5.7)$ \\
\hline \multirow[t]{3}{*}{ Marital status of the mother } & Single & $15(4.3)$ & $16(4.6)$ \\
\hline & Married & $72(20.6)$ & 136(38.9) \\
\hline & Divorced/Separated & $30(8.6)$ & $74(21.2)$ \\
\hline \multirow[t]{3}{*}{ Care giver's Educational status } & Non-educated & $55(15.9)$ & $74(21.3)$ \\
\hline & Primary & $38(11.0)$ & $107(30.8)$ \\
\hline & Secondary or above & $24(6.9)$ & $49(14.1)$ \\
\hline \multirow{2}{*}{ Care giver's residence } & Rural & $33(9.5)$ & $109(31.4)$ \\
\hline & Urban & $84(24.2)$ & $121(34.9)$ \\
\hline \multirow[t]{2}{*}{ Caregiver being on ART } & Yes & $95(27.1)$ & $190(54.3)$ \\
\hline & No & $22(6.3)$ & $43(12.3)$ \\
\hline \multirow{4}{*}{ The orphanhood of the child } & Both & $26(7.4)$ & $9(2.6)$ \\
\hline & Only Mother & $9(2.6)$ & $31(8.9)$ \\
\hline & Only Father & $4(1.1)$ & $15(4.3)$ \\
\hline & Non-orphan & $78(22.3)$ & $178(50.9)$ \\
\hline \multirow[t]{3}{*}{ Wealth index } & 1.00 & $43(12.3)$ & $30(8.6)$ \\
\hline & 2.00 & $42(12.0)$ & $146(41.7)$ \\
\hline & 3.00 & $32(9.1)$ & $57(16.3)$ \\
\hline \multirow[t]{3}{*}{ Family size } & $<4$ & $9(2.6)$ & $23(6.6)$ \\
\hline & $4-6$ & $49(14.0)$ & $123(35.1)$ \\
\hline & $>6$ & $59(16.9)$ & $87(24.9)$ \\
\hline \multirow[t]{4}{*}{ Household food security } & Not secured & $23(6.6)$ & $33(9.4)$ \\
\hline & Secured & $94(26.9)$ & $198(56.6)$ \\
\hline & 3 & $0(0.0)$ & $2(0.6)$ \\
\hline & 3 & $19(5.4)$ & $4(1.1)$ \\
\hline \multirow[t]{2}{*}{ Sex of child } & Male & $67(19.1)$ & $101(28.9)$ \\
\hline & Female & $50(14.3)$ & $132(37.7)$ \\
\hline \multirow[t]{3}{*}{ Grouped caregiver's age } & 1 & $22(6.5)$ & $23(6.7)$ \\
\hline & 2 & $57(16.7)$ & $107(31.4)$ \\
\hline & 3 & $37(10.9)$ & $95(27.9)$ \\
\hline \multirow[t]{3}{*}{ Orphan status of the child } & 1 & $85(24.3)$ & $139(39.7)$ \\
\hline & 2 & $32(9.1)$ & $55(15.7)$ \\
\hline & 4 & $0(0.0)$ & $39(11.1)$ \\
\hline \multirow[t]{3}{*}{ Age of the child } & $1-5$ & $69(22.4)$ & $69(22.4)$ \\
\hline & $5-10$ & $31(10.1)$ & $76(24.7)$ \\
\hline & $10-18$ & $17(5.5)$ & $46(14.9)$ \\
\hline
\end{tabular}




\section{Nutrition, disease, and drug-related predictors of anemia among children on HAART}

This study revealed that $36.6 \%$ of children on HAART, $62(17.7 \%)$ of cases and $66(18.9 \%)$ controls had a history of severe acute malnutrition. Similarly, $86(24.6 \%)$ of cases and $114(32.6 \%)$ controls had a history of opportunistic infections. The proportion of malaria infection was around two times higher among cases, 58 (16.6\%) than controls, 31 (8.9\%). Besides, the proportion of having low CD4-count (<350) was approximately 6 folds higher among cases $56(16.0 \%)$ compared to controls, 10 (2.9\%). Regarding HAART, the proportion of poor adherence was around three times higher among cases $16(4.6 \%)$ compared to controls $5(1.4 \%)$ (Table-3).

\begin{tabular}{|c|c|c|c|}
\hline \multirow[t]{2}{*}{ Exposure variable } & \multirow[t]{2}{*}{ Responses } & \multicolumn{2}{|c|}{ Anemia Status } \\
\hline & & $\begin{array}{c}\text { Anemic } \\
\text { Count (\%) }\end{array}$ & $\begin{array}{c}\text { Non-anemic } \\
\text { Count (\%) }\end{array}$ \\
\hline \multirow[t]{5}{*}{ Intestinal parasite } & Negative & $101(28.9)$ & $79(22.6)$ \\
\hline & G. lamblia & $15(4.3)$ & $145(41.4)$ \\
\hline & E.Histoletica & $1(0.3)$ & $9(2.6)$ \\
\hline & A. lumbricoides & $7(1.2)$ & $9(1.6)$ \\
\hline & Others & $6(1.1)$ & $8(1.5)$ \\
\hline \multirow[t]{3}{*}{ WGT-AGE Z score } & $-1 \_-2$ & $44(12.6)$ & $166(47.4)$ \\
\hline & $-2-3$ & $22(6.3)$ & $31(8.9)$ \\
\hline & $<-3$ & $51(14.6)$ & $36(10.3)$ \\
\hline \multirow[t]{2}{*}{ Hx oropharyngeal disease } & Yes & $37(10.6)$ & $46(13.1)$ \\
\hline & No & $80(22.9)$ & $187(53.4)$ \\
\hline \multirow[t]{2}{*}{ Hx of opportunistic infections } & Yes & $86(24.6)$ & $114(32.6)$ \\
\hline & No & $31(8.9)$ & $119(34.0)$ \\
\hline \multirow[t]{2}{*}{ Hx of chronic diarrhea } & Yes & $51(14.6)$ & $40(11.4)$ \\
\hline & No & $66(18.9)$ & 193(55.1) \\
\hline \multirow[t]{2}{*}{ Hx of missing follow up } & Yes & $56(16.0)$ & $67(19.1)$ \\
\hline & No & $61(17.4)$ & $166(47.4)$ \\
\hline \multirow[t]{2}{*}{ HAART_duration } & $\leq 5$ years & $80(22.9)$ & 177(50.6) \\
\hline & $>5$ years & $37(10.6)$ & $56(16.0)$ \\
\hline \multirow[t]{3}{*}{ Level of adherence to HAART } & Good & $42(12.0)$ & $162(46.3)$ \\
\hline & Fair & $59(16.9)$ & $66(18.9)$ \\
\hline & Poor & $16(4.6)$ & $5(1.4)$ \\
\hline \multirow[t]{2}{*}{ On Cotrimoxazole } & Yes & $64(18.3)$ & $106(30.3)$ \\
\hline & No & $53(15.1)$ & $127(36.3)$ \\
\hline \multirow[t]{2}{*}{ Viral Load } & $<1000$ & $51(14.6)$ & $67(19.1)$ \\
\hline & $>1000$ & $66(18.9)$ & $166(47.4)$ \\
\hline \multirow{2}{*}{ Malaria history } & Yes & $58(16.6)$ & $31(8.9)$ \\
\hline & No & $59(16.9)$ & $202(57.7)$ \\
\hline \multirow[t]{4}{*}{ Highest WHO staging } & Stage 4 & $21(6.0)$ & $33(9.4)$ \\
\hline & Stage 3 & $51(14.6)$ & $108(30.9)$ \\
\hline & Stage 2 & $32(9.1)$ & $67(19.1)$ \\
\hline & Stage 1 & $13(3.7)$ & $25(7.1)$ \\
\hline \multirow[t]{2}{*}{ Household food security } & Not secured & $23(6.6)$ & $33(9.4)$ \\
\hline & Secured & $94(26.9)$ & $200(57.2)$ \\
\hline \multirow[t]{2}{*}{ Food diversity } & Non-diversified & $99(28.3)$ & $87(24.9)$ \\
\hline & Diversified & $18(5.1)$ & $146(41.7)$ \\
\hline \multirow[t]{2}{*}{ Feeding frequency } & Not adequate & $49(14.0)$ & $44(12.6)$ \\
\hline & Adequate & $68(19.4)$ & $189(54.0)$ \\
\hline \multirow{2}{*}{ Counseling on child feeding } & Yes & $76(21.7)$ & $175(50.0)$ \\
\hline & No & $41(11.7)$ & $58(16.6)$ \\
\hline
\end{tabular}




\section{Regression analysis on factors associated with anemia among children on HAART}

Bivariate logistic regression analysis was done for different predictor variables. Intestinal parasite, WGT-AGE Z score, history of oro-pharyngeal disease, history of opportunistic infections, history of chronic diarrhea, history of Missing Follow up, HAART duration, Level of Adherence to HAART, on Cotrimoxazole, Viral Load, Malaria history, Highest WHO staging, Care giver's residence, Orphanhood of the child, Wealth Index, household food security, Food diversity, Feeding frequency, Counseling on child feeding, were significantly associated with the HGB level of respondents. All variables with $P$ value less than 0.25 were fitted into the backward stepwise multivariate logistic regression model. But, on multivariate analysis, having parasitic infections, history of opportunistic infections, being malnourished, poor adherence to ART, caregivers living in the rural area and eating non-diversified foods were significantly associated with anemia among HIV positive children on HAART.

The odds of being anemic among HIV positive children on HAART who had Amebiasis was around 7 times higher than those who had no Amebiasis (AOR = 7.29, 1.22 - 43.56). Similarly, the odds of children on HAART who had a history of opportunistic infections was about 10 times higher to be anemic compared to those who had no history of opportunistic infections (AOR = 9.63, 1.94 - 47.85). The odds of being anemic among children on HAART who had malaria infection (malaria pf) was also around 4 folds higher than those who have no malaria infection (AOR = 4.37, $1.16-16.42$ )

Eating non-diversified foods was found to be significantly associated with anemia among children on HAART. The odds of being anemic among HIV positive children on HAART, who eat non-diversified foods was about 10 folds higher than those who eat diversified foods ( $A O R=10.39,2.25-48.0$ ). At the same time, the odds of children on HAART with WGT -Age Z score value between -2 - 3 was also about 10 times higher to be anemic than those with WGT -Age Z score value between 1_-2 (AOR = 9.80, $2.46-39.14)$.

The odds of children on HAART who have poor adherence to ART drugs were two times higher compared to those who have good adherence $(A O R=2.31,1.92,7.77)$. Besides, caregivers residence was also significantly associated with anemia. The odds of being anemic among children on HAART whose caregiver living in the rural area was approximately 9 folds higher than those whose caregiver living in an urban area ( $A O R=8.8,2.07$ - 37.79) (Table 4).

\section{Table 4: Regression analysis on predictors of anemia among children on HAART in North Wollo Zone public hospitals, Amhara region, Ethiopia, $2019(n=350)$.}




\begin{tabular}{|c|c|c|c|c|c|c|}
\hline \multirow[t]{2}{*}{$\begin{array}{l}\text { Exposure } \\
\text { variable }\end{array}$} & \multirow[t]{2}{*}{ Responses } & \multicolumn{2}{|c|}{ Anemia Status } & \multicolumn{2}{|c|}{$\begin{array}{l}\text { Bivariate and multivariate } \\
\text { regression analysis }\end{array}$} & \multirow[b]{2}{*}{$\begin{array}{c}\mathrm{P}- \\
\text { value }\end{array}$} \\
\hline & & $\begin{array}{l}\text { Anemic } \\
\text { Count } \\
(\%)\end{array}$ & $\begin{array}{l}\text { Non- } \\
\text { anemic } \\
\text { Count } \\
\text { (\%) } \\
\end{array}$ & $\begin{array}{c}\text { COR } \\
(95 \% \mathrm{CI})\end{array}$ & $\begin{array}{c}\text { AOR } \\
(95 \% \mathrm{CI})\end{array}$ & \\
\hline \multirow{5}{*}{$\begin{array}{l}\text { Intestinal } \\
\text { parasite }\end{array}$} & Negative & $101(28.9)$ & $79(22.6)$ & 1 & 1 & \\
\hline & G. lamblia & $15(4.3)$ & $145(41.4)$ & $9.09(4.83,17.11)$ & $0.1(.02, .49)$ & .005 \\
\hline & E.Histoletica & $1(0.3)$ & $9(2.6)$ & $9.54(4.71,19.35)$ & $7.29(1.22,43.56)$ & .029 \\
\hline & $\begin{array}{c}A . \\
\text { lumbricoides }\end{array}$ & $7(1.2)$ & $9(1.40$ & $7.19(2.49,20.69)$ & $.63(.06,6.39)$ & .694 \\
\hline & Others & $6(1.1)$ & $8(1.3)$ & $7.46(2.43,22.94)$ & $2.49(.27,23.01)$ & .422 \\
\hline \multirow{3}{*}{$\begin{array}{l}\text { WGI-AGE } Z \\
\text { score }\end{array}$} & $-1 \_-2$ & $44(12.6)$ & $166(47.4)$ & 1 & 1 & \\
\hline & $-2-3$ & $22(6.3)$ & $31(8.9)$ & $2.67(1.41,5.07)$ & $9.80(2.46,39.14)$ & .001 \\
\hline & $<-3$ & $51(14.6)$ & $36(10.3)$ & $5.35(3.11,9.18)$ & $2.46(.63,9.69)$ & .198 \\
\hline \multirow{2}{*}{$\begin{array}{l}\text { Hx } \\
\text { oropharyngeal } \\
\text { disease }\end{array}$} & Yes & $37(10.6)$ & $46(13.1)$ & $1.88(1.13,3.12)$ & .40(.10,1.57) & 187 \\
\hline & No & $80(22.9)$ & $187(53.4)$ & 1 & 1 & \\
\hline $\mathrm{Hx}$ of & Yes & $86(24.6)$ & $114(32.6)$ & $1.88(1.13,3.12)$ & $9.63(1.94,47.85)$ & .006 \\
\hline $\begin{array}{l}\text { opportunistic } \\
\text { infections }\end{array}$ & No & $31(8.9)$ & $119(34.0)$ & 1 & 1 & \\
\hline Hx of chronic & Yes & $51(14.6)$ & $40(11.4)$ & $2.89(1.78,4.70)$ & $1.05(.23,4.87)$ & .949 \\
\hline diarrhea & No & $66(18.9)$ & 193(55.1) & 1 & 1 & \\
\hline $\mathrm{Hx}$ of Missing & Yes & $56(16.0)$ & $67(19.1)$ & $3.73(2.26,6.14)$ & .38(.09,1.54) & 174 \\
\hline Follow up & No & $61(17.4)$ & $166(47.4)$ & 1 & 1 & \\
\hline \multirow[t]{2}{*}{ HAART_duration } & $\leq 5$ years & $80(22.9)$ & 177(50.6) & $1.46(.89,2.39)$ & $2.33(.69,7.94)$ & 175 \\
\hline & $>5$ years & $37(10.6)$ & $56(16.0)$ & 1 & 1 & \\
\hline Level of & Good & $72(20.6)$ & $132(37.7)$ & 1 & 1 & \\
\hline Adherence to & Fair & $59(16.9)$ & $66(18.9)$ & $1.64(2.10,5.56)$ & $1.33(.69,7.94)$ & .175 \\
\hline HAART & Poor & $13(3.7)$ & $8(2.3)$ & $3.0(4.18,9.63)$ & $2.31(1.92,7.77)$ & .000 \\
\hline On & Yes & $64(18.3)$ & $106(30.3)$ & $1.45(93,2.26)$ & $.33(.09(1.14)$ & .079 \\
\hline Cotrimoxazole & No & $53(15.1)$ & $127(36.3)$ & 1 & 1 & \\
\hline \multirow{2}{*}{ Viral Load } & $<1000$ & $51(14.6)$ & $67(19.1)$ & $1.92(1.21,3.04)$ & $1.09(.23,5.18)$ & .92 \\
\hline & $>1000$ & $66(18.9)$ & $166(47.4)$ & 1 & 1 & \\
\hline \multirow{2}{*}{ Malaria history } & Yes & $58(16.6)$ & $31(8.9)$ & $6.41(3.79,10.82)$ & $4.37(1.16,16.42)$ & .029 \\
\hline & No & $59(16.9)$ & $202(57.7)$ & 1 & 1 & \\
\hline \multirow{4}{*}{$\begin{array}{l}\text { Highest WHO } \\
\text { staging }\end{array}$} & Stage 4 & $21(6.0)$ & $33(9.4)$ & $1.22(.52,2.91)$ & $.01(.00, .16)$ & .002 \\
\hline & Stage 3 & $51(14.6)$ & 108(30.9) & $.91(.43,1.919)$ & $.03(.00, .26)$ & .002 \\
\hline & & & & $.92(.42,2.03)$ & $.022(.00, .23)$ & .001 \\
\hline & Stage 1 & 13(3.7) & $25(7.1)$ & 1 & 1 & \\
\hline \multirow{6}{*}{$\begin{array}{l}\text { Care giver's } \\
\text { residence } \\
\text { The orphanhood } \\
\text { of the child }\end{array}$} & Rural & $33(9.5)$ & $109(31.4)$ & $2.28(1.41,3.67)$ & $8.85(2.07,37.79)$ & .003 \\
\hline & Urban & $84(24.2)$ & $121(34.9)$ & 1 & 1 & \\
\hline & Both & $26(7.4)$ & $9(2.6)$ & $6.59(2.95,14.72)$ & $7.92(.66,94.77)$ & .102 \\
\hline & Only mother & $9(2.6)$ & $31(8.9)$ & $.66(.30,1.46)$ & $.74(.15,3.50)$ & .699 \\
\hline & Only father & $4(1.1)$ & $15(4.3)$ & .61(.19,1.89) & $2.31(.17,31.62)$ & .529 \\
\hline & Non-Orphan & $78(22.3)$ & $178(50.9)$ & 1 & 1 & \\
\hline \multirow[t]{3}{*}{ Wealth Index } & 1.00 & $43(12.3)$ & $30(8.6)$ & $2.55(1.35,4.82)$ & $.64(.09,4.84)$ & .665 \\
\hline & 2.00 & $42(12.0)$ & $146(41.7)$ & $.51(.29, .89)$ & $.76(.17,3.26)$ & .707 \\
\hline & 3.00 & $32(9.1)$ & $57(16.3)$ & 1 & 1 & \\
\hline \multirow{2}{*}{$\begin{array}{l}\text { Household food } \\
\text { security }\end{array}$} & Not secured & $23(6.6)$ & $33(9.4)$ & $1.48(.83,2.66)$ & $.43(.07,2.75)$ & .370 \\
\hline & Secured & $94(26.9)$ & $200(57.2)$ & 1 & 1 & \\
\hline \multirow[t]{2}{*}{ Food diversity } & $\begin{array}{c}\text { Non- } \\
\text { diversified }\end{array}$ & $99(28.3)$ & $87(24.9)$ & $9.23(5.23,16.28)$ & $10.39(2.25,48.0)$ & .003 \\
\hline & & 18(5.1) & $146(41.7)$ & 1 & 1 & \\
\hline \multirow{2}{*}{$\begin{array}{l}\text { Feeding } \\
\text { frequency }\end{array}$} & Not & $49(14.0)$ & $44(12.6)$ & $9.23(5.23,16.29)$ & $1.62(.35,7.59)$ & .539 \\
\hline & $\begin{array}{l}\text { Adequate } \\
\text { Adequate }\end{array}$ & & & 1 & 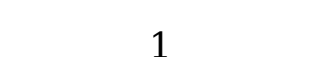 & \\
\hline Counseling on & Yes & $76(21.7)$ & $175(50.0)$ & 1 & 1 & \\
\hline
\end{tabular}




\section{Discussion}

Anemia is a common co-morbid condition among HIV infected children and has a profound impact on disease progression and has been noted as a significant predictor of decreased survival time and death $(14,15)$. Especially children are more prone to the consequences of anemia due to high iron requirements, low intake of iron from foods, and frequent episodes of infection (10).

In Ethiopia, there is limited information about the determinant factors associated with anemia among HIV positive children. Hence, this study aimed to determine the determinant factors of anemia among HIV infected children on HAART.

This case-control study included socio-demographic variables like residence, occupation of mothers, household wealth index status, and disease-related variables like history malaria and opportunistic infections. It also included drug-related and nutrition-related variables like HAART duration, HAART regimen, dietary diversity score and nutritional status of children.

In this study, having parasitic infections, history of opportunistic infections, being malnourished, poor adherence to ART, caregivers living in a rural area and eating non-diversified foods were significantly associated with anemia among HIV positive children on HAART (Table-4).

This study result revealed that the odds of being anemic among HIV positive children on HAART who had Amebiasis was around 7 times higher than those who had no Amebiasis. This might be because children with Amebiasis might cause dysentery which will result in GI blood loss()

Similarly, the odds of being anemic among children on HAART who had malaria infection (malaria pf) was also around 4 folds higher than those who have no malaria infection. This finding is in line with a study conducted at Zewditu Memorial Hospital, Ethiopia in which intestinal parasites and malaria were independently associated with the odds of being anemic (20). It is also consistent with research in south-central Ethiopia in that the risk of anemia was high (adjusted Hazard Ratio $=10$ ) among children with malaria (25). The possible justification for this might be due to falcifarum malaria can cause hemolysis which in turn results in hemolytic anemia.

Similarly, research from Addis Ababa, Ethiopia revealed having intestinal parasitic infections $(\mathrm{AOR}=2.7,95 \% \mathrm{Cl}, 1.1-7.2)$ were identified as significant predictors of anemia (26). This might be because some parasitic infections including malaria are the major causes of blood loss and destruction of red blood cells.

The odds of children on HAART who had a history of opportunistic infections was about 10 times higher to be anemic compared to those who had no history of opportunistic infections. This is consistent with a study at Zewditu Memorial Hospital in which TB-HIV co-infection was independently associated with the odds of being anemic (20). This could be because children who have been attacked with the opportunistic infection will have a loss of appetite and more likely to be malnourished, which is a significant predictor of anemia.

Eating non-diversified foods was found to be significantly associated with anemia among children on HAART. The odds of being anemic among HIV positive children on HAART, who eat non-diversified foods was about 10 folds higher than those who eat diversified foods. This is consistent with a research finding from Waghimra, Northeast Ethiopia which revealed poor dietary diversity being significantly associated with anemia (29). This is because when children got diversified food they will have access to iron-rich foods which will prevent iron deficiency anemia.

The odds of children on HAART with WGT -Age Z score value between -2_-3 was also about 10 times higher to be anemic than those with WGT -Age Z score value between -1_-2. This is in line with findings of other studies in which 
stunting and vitamin A deficiency were identified as an independent risk factor for anemia $(21,29)$. This might be because malnourished children will have associated iron deficiency which is the most common cause of anemia.

The odds of children on HAART who have poor adherence to ART drugs were two times higher compared to those who have good adherence $(A O R=2.31,1.92,7.77)$. The possible justification for this might be those children with poor adherence are at higher risk of developing opportunistic infections which intern results in anemia.

Besides, caregivers residence was also significantly associated with anemia. The odds of being anemic among children on HAART whose caregiver living in a rural area was approximately 9 folds higher than those whose caregiver living in an urban area. This is in line with the 2016 EDHS report in which children in rural areas were more likely to be anemic than those in urban areas ( 57 percent and 47 percent respectively). This might be because children family from urban resident have better consumptions of diversified foods; in addition to this, the prevalence of intestinal parasites is low in urban.

\section{Abbreviations And Acronyms}

ART: Antiretroviral Therapy; CD4: Cluster of Differentiation; EDHS: Ethiopia Demographic; Health Survey; HAART: Highly Active Antiretroviral Therapy; HAZ: Height-For-Age Z-Score; HIV/AIDS: Human Immunodeficiency Virus /Acquired immune deficiency syndrome; SPSS: Statistical Package for Social Science; WHO: World Health Organization; MUAC: Mid Upper Arm Circumference; WAZ: Weight-for-Age Z score; WHZ: Weight-For-Height/Length Z score

\section{Declarations}

\section{Ethics approval and consent to participate}

Ethical clearance was obtained from the Woldia University research project office. Permission and support letter was sought and obtained from the North Wollo Zone Health Office. Then, officials at different levels in the hospitals were communicated through letters. The responsible bodies at each hospital were told about the purpose of the study. Written informed consent was obtained from parents of every study participants after a detailed explanation on the purpose and benefit of the study right before data collection and assent was obtained from the study participants. The respondents were notified that they have the right to refuse or terminate at any point during data collection. All data collectors and supervisors were instructed on how to comply with strict confidentiality practices for all participants both during and after data collection. The identity of the participants was kept anonymous.

\section{Consent for publication}

Note applicable.Availability of data and materialsData is available and it can be accessed from the corresponding author when asked with a reasonable inquiry.

\section{Competing interests}

The authors declare that they have no competing interests.

\section{Funding}

None

\section{Authors' contributions}

Page 15/18 
BB AM, and MA participated in all steps of the study from its commencement to writing. BB and AM participated in analysis and write-up. All the authors had reviewed and approved the submission of the paper.

\section{Acknowledgments}

First, we would like to thank Woldia University, faculty of health science for giving us this opportunity. We would also like to thanks North Wollo Zone Health Office for their cooperation and provision of information related to the study area and study population. Our appreciation also extends to the managers of the hospitals and study participants who participated in the study. Finally, we would like to thank data collectors and supervisors for their contribution to the completion of this study.

\section{Authors' information}

All Authors are permanent workers at Woldia University, Faculty of Health Sciences, and Department of Nursing: P. O. Box 400, Woldia, Ethiopia.

\section{Rreferences}

1.Denue BA, Bello HS, Abja AU, Bukar AA. Changes in blood profile of human immunodeficiency virus (HIV)-infected patients on highly active antiretroviral therapy (HAART) in North-Eastern Nigeria. Journal of AIDS and HIV Research. 2013;5(8):284-91.

2.Katemba C, Muzoora C, Muwanguzi E, Mwambi B, Atuhairwe C, Taremwa IM. Hematological abnormalities in HIVantiretroviral therapy naïve clients as seen at an immune suppression syndrome clinic at Mbarara Regional Referral Hospital, southwestern Uganda. Journal of blood medicine. 2018;9:105.

3.Thulasi RR, Manimaran D, Hemanathan G, Afroz T, Sagar R. Hematological abnormalities in HIV infected individuals in correlation to CD4 counts and ART status. Asian Journal of Medical Sciences. 2016;7(4):14-8.

4.Tsiakalos A, Routsias JG, Kordossis T, Moutsopoulos HM, Tzioufas AG, Sipsas NV. Fine Epitope Specificity of Antierythropoietin Antibodies Reveals Molecular Mimicry With HIV-1 p17 Protein: A Pathogenetic Mechanism for HIV-1Related Anemia. Journal of Infectious Diseases. 2011;204(6):902-11.

5.Ebonyi AO, Oguche S, Ochoga MO, Agbaji OO, Anejo-Okopi JA, Abah IO, et al. Changes in the hematological parameters of HIV-1 infected children at 6 and 12 months of antiretroviral therapy in a large clinic cohort, North-Central Nigeria. Journal of virus eradication. 2017;3(4):208.

6.Taremwa IM, Muyindike WR, Muwanguzi E, Boum Y. Prevalence of HIV-related thrombocytopenia among clients at Mbarara Regional Referral Hospital, Mbarara, southwestern Uganda. Journal of blood medicine. 2015;6:109.

7.Ezeonwu B, Ikefuna A, Oguonu T, Okafor H. Prevalence of hematological abnormalities and malnutrition in HIV-infected under-five children in Enugu. Nigerian Journal of clinical practice. 2014;17(3):303-8.

8.Mathews SE, Srivastava D, BalaYadav R, Sharma A. Association of a hematological profile of human immunodeficiency virus-positive patients with clinicoimmunologic stages of the disease. Journal of laboratory physicians. 2013;5(1):34.

9.Kibaru EG, Nduati R, Wamalwa D, Kariuki N. Impact of highly active antiretroviral therapy on hematological indices among HIV-1 infected children at Kenyatta National Hospital-Kenya: a retrospective study. AIDS research and therapy. 2015;12(1):26. 
10.Organization WH. Hemoglobin concentrations for the diagnosis of anemia and assessment of severity. Geneva, Switzerland: World Health Organization; 2011. Contract No: WHO/NMH/NHD/MNM/111. 2014.

11.Central Statistical Agency EalEdahs. Key Indicators Report. In: Addis Ababa, Ethiopia, and Rockville. Maryland, USA: CSA and ICF; 2016.12:25-54 Google Scholar.

12.Camara-Lemarroy CR, Flores-Cantu H, Calderon-Hernandez HJ, Diaz-Torres MA, Villareal-Velazquez HJ. Drug-induced hemolysis, renal failure, thrombocytopenia and lactic acidosis in patients with HIV and cryptococcal meningitis: a diagnostic challenge. International Journal of STD \& AIDS. 2015;26(14):1052-4.

13.Meidani M, Rezaei F, Maracy MR, Avijgan M, Tayeri K. Prevalence, severity, and related factors of anemia in HIV/AIDS patients. Journal of research in medical sciences: the official journal of Isfahan University of Medical Sciences. 2012;17(2):138.

14. Chatterjee A, Bosch RJ, Kupka R, Hunter DJ, Msamanga GI, Fawzi WW. Predictors and consequences of anemia among antiretroviral-naive HIV-infected and HIV-uninfected children in Tanzania. Public health nutrition. 2010;13(2):289-96.

15.Quaye W, Addai-Mensah A. Prevalence of anemia and immunological markers among Ghanaian HAART-naïve HIVpatients and those on HAART. African Health Sciences. 2011;11(1).

16.Benoist Bd, McLean E, Egll I, Cogswell M. Worldwide prevalence of anemia 1993-2005: WHO global database on anemia. Worldwide prevalence of anemia 1993-2005: WHO global database on anemia. 2008.

17.Enawgaw B, Alem M, Melku M, Addis Z, Terefe B, Yitayew G. Prevalence and associated risk factors of anemia among HIV infected children attending Gondar university hospital, Northwest Ethiopia: a cross-sectional study. BMC Hematology. 2015;15(1):12.

18.Lumbiganon P, Kosalaraksa P, Bunupuradah T, Boettiger D, Saphonn V, Truong KH, et al. HIV-infected children in the Asia-Pacific region with baseline severe anemia: antiretroviral therapy and outcomes. Asian Biomedicine. 2016;10(3):22934.

19.Mekonnen W, Worku A. Determinants of low family planning use and high unmet need in Butajira District, South Central Ethiopia. Reproductive Health. 2011;8(1):37.

20.Assefa M, Abegaz WE, Shewamare A, Medhin G, Belay M. Prevalence and correlates of anemia among HIV infected patients on highly active antiretroviral therapy at Zewditu Memorial Hospital, Ethiopia. BMC Hematology. 2015;15(1):6.

21.Shet A, Bhavani P, Kumarasamy N, Arumugam K, Poongulali S, Elumalai S, et al. Anemia, diet and therapeutic iron among children living with HIV: a prospective cohort study. BMC pediatrics. 2015;15(1):164.

22.Subbaraman R, Devaleenal B, Selvamuthu P, Yepthomi T, Solomon SS, Mayer KH, et al. Factors associated with anemia in HIV-infected individuals in southern India. International Journal of STD \& AIDS. 2009;20(7):489-92.

23.Ruhinda EN, Bajunirwe F, Kiwanuka J. Anaemia in HIV-infected children: severity, types, and effect on response to HAART. BMC pediatrics. 2012;12(1):170.

24.Ahumareze RE, Rankin J, David A, Wapmuk A, Disu E, Balogun Y, et al. Prevalence of anemia and the relationship between hemoglobin concentration and CD4 count in HIV positive children on highly active antiretroviral therapy (HAART) in Lagos, Nigeria. Current Pediatric Research. 2016;20(1).

Page $17 / 18$ 
25.Gari T, Loha E, Deressa W, Solomon T, Atsbeha H, Assegid M, et al. Anaemia among children in a drought-affected community in south-central Ethiopia. PloS one. 2017;12(3):e0170898.

26. Mihiretie H, Taye B, Tsegaye A. Magnitude of anemia and associated factors among pediatric HIV/AIDS patients attending Zewditu Memorial Hospital ART Clinic, Addis Ababa, Ethiopia. Anemia. 2015;2015.

27.Teklemariam Z, Mitiku H, Mesfin F. Prevalence of anemia and nutritional status among HIV-positive children receiving antiretroviral therapy in Harar, eastern Ethiopia. HIV/AIDS (Auckland, NZ). 2015;7:191.

28.Ngongondo M, Rosenberg NE, Stanley CC, Lim R, Ongubo D, Broadhurst R, et al. Anemia in people on second-line antiretroviral treatment in Lilongwe, Malawi: a cross-sectional study. BMC infectious diseases. 2018;18(1):39.

29.Woldie H, Kebede Y, Tariku A. Factors associated with anemia among children aged 6-23 months attending growth monitoring at Tsitsika Health Center, Wag-Himra Zone, Northeast Ethiopia. Journal of nutrition and metabolism. $2015 ; 2015$.

30.Cinta M RA, Tacilta N. Anemia in hospitalized preschool children from a rural area in Mozambique: a case-control study in search for aetiological agents

2017;17:63-78.

31.Organization. WH. Hemoglobin concentrations for the diagnosis of anemia and assessment of severity, Vitamin and Mineral Nutrition Information System. Geneva: World Health Organization. Accessed 2 May 2015. Available at http://www.who.int/vmnis/indicators/haemoglobin/en/.

32.Anticona C, San Sebastian M. Anemia and malnutrition in indigenous children and adolescents of the Peruvian Amazon in a context of lead exposure: a cross-sectional study. Global health action. 2014;7(1):22888.

33.Organization WH. Guideline: daily iron and folic acid supplementation in pregnant women: World Health Organization; 2012.

34.Organization WH. Hemoglobin concentrations for the diagnosis of anemia and assessment of severity. 2011. 